\title{
Nocturnal Enuresis In Children
}

\author{
Asiya Kazi, Syed Ijaz Hussain Zaidi, Khemchand, Faisal Faheem
}

\begin{abstract}
:
Nocturnal enuresis is one of the commonest developmental problem specially in our country. It can cause emotional family stress and social isolation of child. According to WHO if condition persist after six years of age, it should be consider as pathological. Exact cause of this condition is not known but is common in lower socio economic people due to lack of awareness about the impact of this disease on the psychology of the children. Different modalities of treatment comprising of non-Pharmacotherapy as well as pharmacotherapy are being tried but relapse rate still persist. In non-pharmacotherapy: Psychotherapy, toilet training and alarm therapy has been tried but in pharmacotherapy, monotherapy that is desmopressin and imipramine and combination of therapy that is desmopressin + oxybutynin and desmopressin + imipramine has been tried. Multiple studies are available but relapse rate till exist. Combination therapy (desmopressin + oxybutynin) is being tried in various Tertiary care Hospital of Pakistan and results are encouraging.
\end{abstract}

Keywords: children, combination therapy, desmopressin, imipramine, Nocturnal enuresis, oxybutynin.

\section{INTRODUCTION:}

Nocturnal enuresis is commonest problem in children all over the world. ${ }^{1}$ The child failed to control over automatic passage of urine at any time of a day during sleep beyond the age of 5yrs. It is more in boys but diurnal enuresis is common in girls. ${ }^{2}$ If this condition persists after 6yrs then it should be considered as pathological (according to WHO). International children continence society (ICCS) has defined nocturnal enuresis as intermittent involuntary voiding at night which is not having any physical ailments. In minimum of 1 episode a month for at least 3 months is required for diagnosis of this disease. This disease is mainly divided as primary and secondary. In primary, mono-symptomatic nocturnal enuresis (MNE), the child has never attained nocturnal enuresis continuous. It is not associated with other lower urinary tract symptoms (LUTS) or dysfunction of urinary bladders ${ }^{3,4}$.

In Non-symptomatic enuresis (NMNE), it is caused by lower urinary tract infection, increased or decreased frequency of urine, urgency, hesitancy, straining and feeling of incomplete emptying of bladders. In this condition the child have achieved 6 months of nocturnal dryness. There is just a $15 \%$

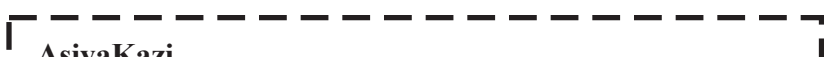

I M.Phil Student Pharmacology

I Bahria University Medical \& Dental College, Karachi

I Syed Ijaz Hussain Zaidi

Associate Professor, Pharmacology

Bahria University Medical \& Dental College, Karachi

I Email:col_zaidi@yahoo.com

I Khemchand

I Professor of Paedriatric Nephrology

I National Institute of Child Health, Karachi

I Faisal Faheem

I Researcher

Bahria University Medical \& Dental College, Karachi

Received: 01-03-2019

Accepted: 25-05-2019 chance that kids to be suffering by NE if the parents were having the history of enuresis. However this increases to $44 \%$ and $77 \%$ if one or the two parents had this problem. ${ }^{5}$ Besides its association with the urinary tract infection, but more important cause is deficiency of antidiuretic hormone.

The correct neuro-physiological process is not known. However, kids accomplish control of bladder at various stages of life. The majority of children usually accomplish by 5 years of age. In the early years, the frequency of urine is because of micturition reflex due to stimulation of para sympathetic system, up to $2 \mathrm{yrs}$ due to expansion of bladder this reflex is decreased and involuntary control of bladder is achieved. At the age of 3yrs control if the internal sphincter of the bladder is attained and urination can be started as well as finished voluntarily. At the age of $5 \mathrm{yrs} 85 \%$ of children manage to fully control the urine. The exact etiology of NE is unknown. However there are various factors which affect NE include genetic heritage, delay in maturation of $\mathrm{CNS}$, lack of regulation of $\mathrm{ADH}$, urinary tract abnormality, bacterial infection, and psychological problems. ${ }^{6,7}$

\section{METHODOLOGY:}

Nocturnal enuresis is socially cumbersome problem which lowers the self-esteem as well as quality of life of both parents and child. A total of 10 articles have been selected from google and search engine i.e. Pub Med/ midline google scholar for the year 2010-2017. Basic concept of nocturnal enuresis has introduced using various keywords like NE, desmopressin, oxybutynin, etiology, pathophysiology and treatment.

\section{LITERATAURE REVIEW}

\section{CLASSIFICATION}

PRIMARY CAUSES:

$\mathbf{9 0} \%$ cases are primary nocturnal enuresis, these are bases on genetic, biological and developmental factors. If one parent is having NE than there is $44 \%$ chances that child is 


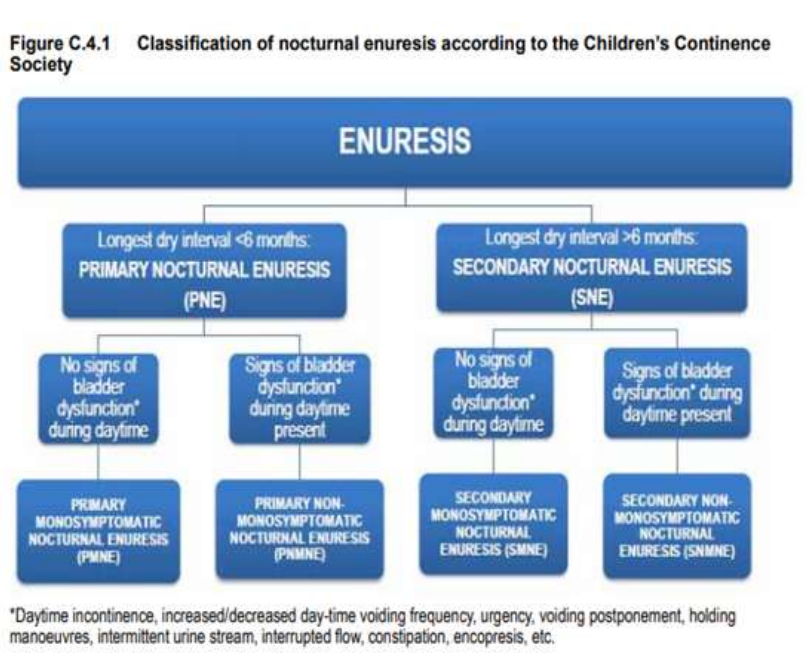

having this disease. If both parents are involved then there are $77 \%$ chances of this disease. It is more common in obese kids. ${ }^{8}$ In USA obesity has significant impact to increase incidence of this disease $(16.9 \%){ }^{9}$ It is mainly associated with sleep disorders, psychological and attention deficit hyperactive disorder which might be related to the morbidity and later on life threatening condition as well. ${ }^{10,11}$

In accordance with ICCS ${ }^{12}$, the bladder dysfunction causes lower urinary tract symptoms (LUTS) with or without constipation. However, there is obvious relation between incontinency and constipation, And there is increased incidence $(30 \%)$ of this disease. ${ }^{13}$ Numerous studies presented positive effects while managing constipation in LUTS/NE of functional constipation on LUTS/enuresis. ${ }^{14,15}$ However, there is obvious relationship between these two symptoms which causes increase incontinency

SECONDARY CAUSES: it mainly included neurological dysfunctions, inherited problem and malformations of urogenital system, infections and psychological disorders. The important secondary cause of NE is constipation which may increase the pressure in the bladder and predisposing to the act of urination. ${ }^{16}$ These subjects need through psychological investigation to identify a treatable cause of the condition. ${ }^{17,18}$ One of the study predicted that history of child abuse was one of the cause of urinary incontinence. ${ }^{19}$, however this condition has also observed in few cases in middle aged individuals as reported by Madhu et al.$^{20}$

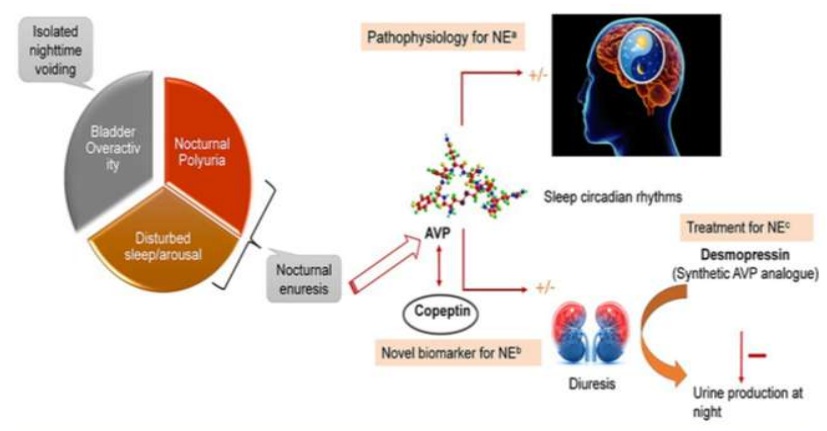

\section{PREVALENCE}

Multiple studies are available which showed that nocturnal enuresis is more prevalent in 5yrs of age (8-20\%), in 10yrs of age $5-10 \%$ and for adults $2-6 \%{ }^{5,21}$ It is more prevalent in boys than in girls. The high incidence of this disease is more in people having low socio economics status. Frequency of this disease is varied in various countries of the world. The variation may be due to the cultural, ethnic, ecological and social factors.

\section{EPIDEMOLOGY}

It is still debatable to know about the exact cause of this disease. Its epidemiology is complex. It is 2 to 3 times more common than the day time urinary in continuous. It is more prevalent in boys than in girls. Primary is more common than secondary enuresis. Mono symptomatic enuresis is 2 times $(69 \%)$ more common than non-mono symptomatic enuresis $(32 \%)$. The prevalence of this disease decreases with the advancement of age and children, however the incidence is decreased every year by $14 \%$ (. If one family member is having this disease the child is most likely to have $48.5 \%$ and if both parents are involved then the chances of this disease is $77 \% .^{22}$

\section{PATHOPHYSICOLOGY}

Exact cause is not known but research has been done and evaluated that the following mechanism are interrelated for its pathophysiology i.e. 1) defective arousal response during sleep when volume of urine exceeds bladder capacity, it causes NE. 2)Due to decrease diurnal rhythm of vasopressin secretion resulting production of excessive urine and caused nocturnal polyuria.3) Bladder over activity resulting in involuntary voiding.4) Acetylcholine act on M3 receptors and relax inter sphincter of bladder and promotes increase passage of urine. ${ }^{23}$

\section{MANAGEMENT:}

In past, the cruel management like beating and punishment was awarded due to lack of knowledge about the adverse impact on child psychology. It is mandatory requirement to create awareness among parents, teachers and treating doctors. Subsequent increase of publications over the last 20 years provided up to date knowledge of this disease in order to improve the understanding of this condition and importance regarding the treatment.

After proper diagnosis of this disorder, habit should be made to evacuate the bladder before sleep and less ingestion of fluids $3-4 \mathrm{hrs}$ are suggested as prior measures. ${ }^{24}$ additionally the medical treatment of constipation is also recommended.

The initial step in managing of NE is recording of history and performing physical examination. While taking history, patients voiding pattern, together with regularity of passing of urine around the clock, morning enuresis and incidence of NE in one week is evaluated. Amount of fluid intake throughout the day time, in evening and additionally prior 
to sleep been evaluated. The step of physical examination includes correct neurological assessment, spinal dysraphism and anomalies of urogenital system. ${ }^{25}$ Urine analysis is done for evaluation of glycosuria which is essential for all patients having night time urinary incontinence. Ultrasonography and other relevant investigations are advised for assessment of any abnormality in urogenital system or to delineate the exact cause of disease ${ }^{26}$

\section{DISCUSSION:}

$\mathrm{NE}$ is very notorious condition affecting the kids and their families. Various options have been formulated for the management of this condition, comprising of non-pharmaco therapy and pharmaco-therapy.

Non-pharmaco therapy includes alarmed therapy that requires training of child and parents. ${ }^{27}$ In this when the bladder is full and due to this technique the child will awake at night and passes urine. ${ }^{28}$ Training of the bladder exercise is to retain the urine for longer time. A research done by Maxwell on 250 patients, He compared the treatment modalities that are drug imipramine with conventional therapy NE is common issue with the age 6-12yrs. Many surveys have been conducted at different educational institutions but definite treatment of NE is still a matter of debate due to unknown pathology, lack of knowledge and awareness among the people. The cumulative incidence rate of enuresis is $25 \%$ in children (6-12yrs)in our study which is very high as compared to other study of various countries. ${ }^{29}$ In Pakistan few studies are available.

$\mathrm{NE}$ is claimed to be related with the excessive production of urine at night when the child is sleeping with signs of bladder fullness. The increase urine formation at night is because of decreased production ADH at night. Therefore existing management of this condition involves utilization of drugs (desmopressin) that increase ADH secretion and help to reduce the over production of urine at night. Another therapy is given by using anticholinergic drug oxybutynin. It acts on the hyperactive bladders and decrease muscle spasm bladder by relaxing internal sphincters of bladder and decrease urgency and frequency of urine. The success rate is $70 \%$, desmopressin $(63 \%)$ and imipramine $(61 \%)^{30}$

\section{CONCLUSION:}

The substantial variation in the monotherapy treatment of enuresis is with desmopressin, imipramine and oxybutynin. In comparison among these drugs oxybutynin's response rate is high while the relapse rate is low. These ambiguities can be cleared by clinical trials with a larger sample size.

Furthermore, there was lack of knowledge and awareness in parents and necessary measures should be taken to formulate awareness programs in order to reduce the burden of the disease.

\section{REFERENCES:}

1. Austin PF, Bauer SB, Bower W, et al. The standardization of terminology of lower urinary tract function in children and adolescents: Update report from the standardization committee of the Interna-tional Children's Continence Society. J Urol 2014;191:1863-5

2. Elder J.S. Enuresis and Voiding Dysfunction. In :Kleigman RM, Stanton BF, Schor NF, St Geme JS ,Behrman RE, editors. Nelson Textbook of Pedistrics. 20th edition. Elsevier;2016.p.2585

3. Eberdt-Golabek B1, Zmyslowska K, Slowik M, Hozyasz k. Etiologyprimary, monosymptomatic nocturnal enuresis inchildren. Own research. Med WiekuRozwoj. 2013;17(4):3139.

4. Sharifiaghdas F, Sharifiaghdas S, Taheri M. Primary Mono Symptomatic Nocturnal Enuresis: Monotherapy versus Combination Therapy. Urology 2016.

5. Sarici H, Telli O, Ozgur BC, Demirbas A, OzgurS,Karagoz MA. Prevalence of nocturnal enuresis and its influence on quality of life in school-aged children.J Pediatric Urol 2015.

6. Schmitt BD. Nocturnal enuresis PedIatrics in Review 1997;18:183-91.

7. Nevéus T. Pathogenesis of enuresis: Towards a new understanding. International journal of urology: official journal of the Japanese Urological Association. 2017;24(3):174-82

8. Weintraub Y, Singer S, Alexander D, et al. Enuresis-an unattended comorbidity of childhood obesity. Int J Obes 2013;37:75-8.

9. CL, Carroll MD, Kit BK, Flegal KM. Prevalence of obesity and trends in body mass index among US children and adolescents, 1999-2010. JAMA 2012;307:483-90.

10. Weintraub Y, Singer S, Alexander D, et al. Enuresis - an unattended comorbidity of childhood obesity. Int J Obes 2013;37:75-8

11. Zahra SS. A prospective longitudinal study to estimate the prevalence of obesity in Egyptian children with nocturnal enuresis and the association between body mass index and response to therapy. Egypt J Med Hum Genet. 2016; 18(3): 1-8.

12. McGrath KH, Caldwell PHY, Jones MP. The frequency of constipation in children with nocturnal enuresis: A comparison with parental reporting. J Paediatr Child Health 2008;44:19-27.

13. Kim JH, Lee JH, Jung AY, Lee JW. The prevalence and therapeutic effect of constipation in pediatric overactive bladder. Int Neurourol J 2011;15:206-10.

14. Austin PF, Coplen DE. Enuresis and dysfunctional elimination. Mo Med 2007;104:421-4.

15. Dal Pra A, Cury FL, Souhami L. Radiation therapy and androgen deprivation in the management of high risk prostate cancer. Int Braz J Urol 2011;37:161-79.

16. Akan S, Ürkmez A, Yildirim C, Sahin A, Yüksel H, Verit A. Late-onset secondary nocturnal enuresis in adolescents associated with post-traumatic stress disorder developed after a traffic accident. Arch Ital UrolAndrol 2015;87:250-1.

17. von Gontard A, Baeyens D, Van Hoecke E, Warzak WJ, Bachmann C. Psychological and psychiatric issues in urinary and fecal inconti-nence. J Urol 2011;185:1432-6.

18. de Jesus LE, Tomé A, Cobe D, Camelier P. Psychosocial and respira tory disease related to severe bladder dysfunction and non-mono-symptomatic enuresis. J Pediatr Urol 2016;12(126):e1-6.

19. Elliott AJ, Peterson LW. Maternal sexual abuse of male children: When to suspect and how to uncover it. Postgrad Med 1993;94: 169-80 
20. Madhu CK, Hashim H, Enki D, Drake MJ. Risk factors and functional abnormalities associated with adult onset secondary nocturnal enuresis in women. NeurourolUrodyn 2017;36:188-91

21. Ozden C, Ozdal OL, Altinova S, Oguzulgen I, Urgancioglu $\mathrm{G}$, Memis A. Prevalence and associated factors of enuresis in Turkish children. International braz j urol. 2007;33(2):21622

22. von Gontard A, Heron J, Joinson C. Family history of nocturnal enuresisand urinary incontinence: results from a large epidemiological study. J Urol. 2011;185(6):2303-6. doi: 10.1016/j.juro.2011.02.040. [PubMed: 21511300].

23. Fig. £ukaszyk E, $\mathrm{Ma}^{3}$ yszko J: Copeptin: Pathophysiology and potential clinical impact. Adv Med Sci. 2015; 60(2): 335-41.PubMed Abstract | Publisher Full Text | F1000 Recommendation

24. Van Herzeele C, Evans J, Eggert P, Lottmann H, Norgaard JP and VandeWalle J: Predictive parameters of response to desmopressin in primary nocturnal enuresis. J PediatrUrol 2015; 11: 200.e1-e8, .

25. Cakiroglu B, Tas T, Eyyupoglu SE, Hazar AI, Can Balci MB, Nas Y, et al.The adverse influence of spina bifida occulta on the medical treatment outcome of primary monosymptomatic nocturnal enuresis. Arch Ital UrolAndrol. 2014;86(4):270-3. doi: 10.4081/aiua.2014.4.270
26. JV, Rittig S, Bauer S, Eggert P, Marschall-Kehrel D, Tekgul $\mathrm{S}$. Practical consensus guidelines for the management of enuresis. Eur J Pediatr. 2012;171:971-83. doi: 10.1007/s00431012-1687-7.

27. Ahmed AF, Amin MM, Ali MM and Shalaby EA: Efficacy of an enuresis alarm, desmopressin, and combination therapy in the treatment of Saudi children with primary monosymptomatic nocturnal enuresis. Korean J Urol 2013; 54: 783-90, .

28. Azevedo Soster L, Alves R, Fagundes SN, Koch VH, Bruni O. Sleep disturbances associated with sleep enuresis: A questionnaire study. European journal of paediatricneurology: EJPN : Official J Eu Paediatric Neurol Soc 2016; 20:282-5.

29. Lundmark E, Nevéus T. Reboxetine in therapy-resistant enuresis: a retrospective evaluation. Scand J UrolNephrol. 2009;43:365-8. doi: 10.3109/00365590903099959

30. Kim S-O, Yu H, Kwon D. Efficacy of desmopressin to treat nocturnal polyuria in elderly men: effects on sleep quality. Urol Int. 2016;96:438-42. doi: 10.1159/000443968 